\title{
(6) OPEN ACCESS \\ Collaborative pharmaceutical care in an Irish hospital: uncontrolled before-after study
}

\author{
Tamasine C Grimes, ${ }^{1,2}$ Evelyn Deasy, ${ }^{1,2}$ Ann Allen, ${ }^{1}$ John O'Byrne, ${ }^{1}$ \\ Tim Delaney, ${ }^{1}$ John Barragry, ${ }^{3}$ Niall Breslin, ${ }^{3}$ Eddie Moloney, ${ }^{3}$ \\ Catherine Wall ${ }^{3}$
}

- Additional material is published online only. To view please visit the journal online (http://dx.doi.org/10.1136/bmjqs2013-002188).

${ }^{1}$ Pharmacy Department, Tallaght Hospital, Dublin, Ireland

${ }^{2}$ School of Pharmacy and Pharmaceutical Sciences, Trinity College Dublin, Ireland ${ }^{3}$ Medical Directorate, Tallaght Hospital, Dublin, Ireland

\section{Correspondence to} Dr Tamasine C Grimes, Pharmacy Department, Tallaght Hospital, Dublin 24, Ireland, tagrimes@tcd.ie

Received 29 May 2013 Revised 12 December 2013

Accepted 14 December 2013 Published Online First

6 February 2014

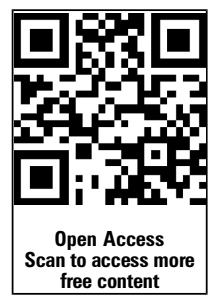

CrossMark

To cite: Grimes TC, Deasy $\mathrm{E}_{\text {, }}$ Allen $A$, et al. BMJ Qual Saf 2014;23:574-583.

\begin{abstract}
Background We investigated the benefits of the Collaborative Pharmaceutical Care in Tallaght Hospital (PACT) service versus standard wardbased clinical pharmacy in adult inpatients receiving acute medical care, particularly on prevalence of medication error and quality of prescribing.

Methods Uncontrolled before-after study, undertaken in consecutive adult medical inpatients admitted and discharged alive, using at least three medications. Standard care involved clinical pharmacists being ward-based, contributing to medication history taking and prescription review, but not involved at discharge. The innovative PACT intervention involved clinical pharmacists being team-based, leading admission and discharge medication reconciliation and undertaking prescription review. Primary outcome measures were prevalence per patient of medication error and potentially severe error. Secondary measures included quality of prescribing using the Medication Appropriateness Index (MAl) in patients aged $\geq 65$ years

Findings Some 233 patients (112 PACT, 121 standard) were included. PACT decreased the prevalence of any medication error at discharge (adjusted OR 0.07 (95\% Cl 0.03 to 0.15)); number needed to treat (NNT) 3 (95\% Cl 2 to 3 ) and no PACT patient experienced a potentially severe error (NNT 20,95\% Cl 10 to 142). In patients aged $\geq 65$ years ( $n=108$ ), PACT improved the MAI score from preadmission to discharge (Mann-Whitney $\mathrm{U} \mathrm{p}<0.05$; PACT median -1 , IQR -3.75 to 0 ; standard care median +1 , IQR -1 to +6).

Conclusions PACT, a collaborative model of pharmaceutical care involving medication reconciliation and review, delivered by clinical pharmacists and physicians, at admission, during inpatient care and at discharge was protective against potentially severe medication errors in acute medical patients and improved the quality of prescribing in older patients.
\end{abstract}

\section{BACKGROUND AND INTRODUCTION}

Periods of patient care that involve a transfer across organisations or transfer between professionals are more vulnerable with regard to medication safety than other periods. ${ }^{1-4}$ Medication error is more prevalent at these junctures and may result in harm: a type of adverse drug event (ADE). Medication reconciliation (here on referred to as MedRec) is a process advocated to prevent harm consequent to reconciliation error, ${ }^{5-9}$ and in some organisations MedRec is required to facilitate accreditation. ${ }^{10}$ MedRec was defined by the Institute for Healthcare Improvement (IHI) 2006 as "the process of obtaining and maintaining an accurate and detailed list of all prescribed and non-prescribed drugs a patient is taking, including dosage and frequency, through all healthcare encounters and comparing the physician's admission, transfer, and/ or discharge orders to that list, recognizing any discrepancies, and documenting any changes, thus resulting in a complete list of medications, accurately communicated". 6 It is time consuming and labour intensive, $^{11} 12$ and scarce resources should be prioritised for it only where there is evidence of its value to care. Two recent systematic reviews investigating hospital-based MedRec practices concluded that while there is a need for further comparative studies, available evidence suggests benefits from interventions that involve pharmacy staff. $^{3} 13$ There is evidence that MedRec interventions should focus on patients at high risk of $\mathrm{ADEs}^{3}{ }^{3}$ for example, those using increasing numbers of medication, having a higher comorbidity burden or being older. ${ }^{2}{ }^{14-16}$ Additionally the prevalence rates of potentially inappropriate prescribing among older ( $\geq 65$ years) patients 
have been cited by authors as being in the range 35$60 \%$ of patients in acute hospitals. ${ }^{17} 18$ The financial and clinical consequences of poor prescribing, caused either by poor prescribing decisions or error, include impact on national drug and healthcare budgets ${ }^{19}{ }^{20}$; drug-related morbidity causing hospitalisation or mortality. ${ }^{14} 21-24$

A number of recent controlled trials have investigated the benefits of complex interventions that involve collaborative medical care and clinical pharmacy activity at admission, during inpatient stay and at discharge. ${ }^{14} \begin{array}{lllll}15 & 21 & 23 & 25 & 26\end{array}$ The interventions have involved close working between clinical pharmacy and medical staff, facilitating integrated management of medicines across the entire inpatient episode. Such integration has been proven to reduce the prevalence of medication error and (re)hospitalisation and to improve the quality of prescribing. ${ }^{14}{ }^{23}{ }^{26-28}$ This accords with statements from the International Pharmaceutical Federation (FIP) that describe a fivelevel model of Collaborative Pharmacy Practice (CPP) with advancing models involving closer collaboration with the medical team and greater responsibility for the pharmacist. ${ }^{29}$ FIP have identified that examples of the most advanced levels of CPP are in place in the UK, USA and Canada, but few elsewhere. ${ }^{29}$

In Ireland, few hospital pharmacy departments are involved in delivering MedRec at admission or discharge. ${ }^{30}{ }^{31}$ Involvement of clinical pharmacists in multidisciplinary clinical activities, with the exception of specialist services, for example, haematology, is rare. ${ }^{31}$ To date, there has been no comparative study undertaken in Ireland to determine the benefits of integrating the clinical pharmacy service with medical care. Evidence is needed to support wider implementation of this model of collaboration in Ireland and worldwide. The purpose of this study was to investigate the benefits of a team-based collaborative model of clinical pharmacy and medical care, the Collaborative Pharmaceutical Care at Tallaght Hospital (PACT) service, on the prevalence per patient of medication error and the quality of prescribing. Standard care comprised a ward-based clinical pharmacy service. The study was undertaken in consecutive adult medical inpatients receiving acute care, admitted and discharged alive during the study period and using at least three regular medications on presentation to hospital.

\section{METHODS}

\section{Study design, setting and sampling}

Ambispective observational uncontrolled before-after study, undertaken at Tallaght Hospital, Dublin, Ireland: a 600-bed acute hospital managing $>17000$ adult inpatient episodes annually. The study was undertaken with four medical teams with a standard care, washout and intervention period for each (table 1), between July 2010 and May 2011 (table 2). The teams all provided
Table 1 Key features of the Pharmaceutical Care in Tallaght Hospital (PACT) intervention and standard care

\begin{tabular}{|c|c|c|}
\hline & Standard care & PACT intervention \\
\hline $\begin{array}{l}\text { Service } \\
\text { arrangement }\end{array}$ & Aligned to a ward & $\begin{array}{l}\text { Aligned to a medical } \\
\text { team }\end{array}$ \\
\hline $\begin{array}{l}\text { Clinical } \\
\text { pharmacists } \\
\text { involved }\end{array}$ & $\begin{array}{l}\text { Service delivered by routine } \\
\text { clinical pharmacists }\end{array}$ & $\begin{array}{l}\text { Service delivered by one } \\
\text { of two PACT clinical } \\
\text { pharmacists }\end{array}$ \\
\hline $\begin{array}{l}\text { Service at } \\
\text { admission }\end{array}$ & $\begin{array}{l}\text { Contributed to admission } \\
\text { medication history taking }\end{array}$ & $\begin{array}{l}\text { Led admission medication } \\
\text { history taking and } \\
\text { reconciliation }\end{array}$ \\
\hline \multirow[t]{2}{*}{$\begin{array}{l}\text { Service during } \\
\text { admission }\end{array}$} & $\begin{array}{l}\text { Made minor changes and } \\
\text { endorsements to the drug } \\
\text { prescription and } \\
\text { administration chart (drug } \\
\text { chart), for example, clarify } \\
\text { an intended formulation or } \\
\text { notate to facilitate } \\
\text { appropriate administration, } \\
\text { for example, 'before food' }\end{array}$ & $\begin{array}{l}\text { Made minor and major } \\
\text { changes to the drug } \\
\text { chart, as required, and } \\
\text { these were co-signed by a } \\
\text { medical practitioner }\end{array}$ \\
\hline & $\begin{array}{l}\text { Delivered routine clinical } \\
\text { pharmacy tasks (drug chart } \\
\text { review; therapeutic drug } \\
\text { monitoring; medication } \\
\text { review; contribution of } \\
\text { suggestions to optimise } \\
\text { medication use and } \\
\text { medication information } \\
\text { queries) }\end{array}$ & $\begin{array}{l}\text { Delivered routine clinical } \\
\text { pharmacy tasks (drug } \\
\text { chart review; therapeutic } \\
\text { drug monitoring; } \\
\text { medication review; } \\
\text { contribution of } \\
\text { suggestions to optimise } \\
\text { medication use and } \\
\text { medication information } \\
\text { queries) }\end{array}$ \\
\hline \multirow[t]{2}{*}{$\begin{array}{l}\text { Service at } \\
\text { discharge }\end{array}$} & No service & $\begin{array}{l}\text { Discharge medication } \\
\text { reconciliation }\end{array}$ \\
\hline & & $\begin{array}{l}\text { Made minor and major } \\
\text { changes to the discharge } \\
\text { medication list, as } \\
\text { required, and these were } \\
\text { co-signed by a medical } \\
\text { practitioner }\end{array}$ \\
\hline
\end{tabular}

general medical care, with the leading consultants having recognised, certified, higher specialist training in endocrinology, gastroenterology, respiratory or renal medicine. In the study hospital, there is no cohorting of patients on wards according to the medical specialty. Adult medical patients, who used three or more regular medications, admitted to and discharged alive from the hospital were eligible for inclusion. Patients readmitted during the study period and staff members admitted as patients were excluded. Consecutive patients who fulfilled the inclusion criteria were recruited.

\section{Standard care and intervention}

The standard care and intervention activities are presented in table 1. Standard care clinical pharmacists were aligned to a ward, serving patients under the care of numerous treating consultants, consistent with Level 3 of the FIP model of CPP. ${ }^{29}$ Approximately two-thirds of standard care clinical pharmacists held National Framework of Qualifications (NFQ) Level 9 (Master), the remainder held NFQ Level 8 (Bachelor). The PACT intervention comprised integrated medication management with the clinical pharmacist aligned 
Table 2 Recruitment of patients and dates of study periods

\begin{tabular}{|c|c|c|}
\hline & Standard & Intervention \\
\hline Assessed for eligibility & 431 & 403 \\
\hline \multicolumn{3}{|l|}{ Excluded, not meeting study criteria } \\
\hline Admitted outside study period & 29 & 33 \\
\hline Discharged outside study period & 58 & 85 \\
\hline Died during hospital stay & 9 & 9 \\
\hline $\begin{array}{l}\text { Used less than three regular } \\
\text { medications at admission }\end{array}$ & 98 & 58 \\
\hline $\begin{array}{l}\text { Transferred to another medical } \\
\text { team during study period }\end{array}$ & 111 & 84 \\
\hline $\begin{array}{l}\text { Readmitted during study period, } \\
\text { already recruited }\end{array}$ & 5 & 22 \\
\hline $\begin{array}{l}\text { Included in study and exposed to } \\
\text { intervention }\end{array}$ & 121 & 112 \\
\hline $\begin{array}{l}\text { Follow-up, primary outcome not } \\
\text { assessable }\end{array}$ & 20 & 4 \\
\hline Primary outcome data analysed & 101 & 108 \\
\hline \multicolumn{3}{|l|}{ Dates of study periods } \\
\hline Team 1 & Jul-Sep 2010 & Oct-Dec 2010 \\
\hline Team 2 & Oct-Dec 2010 & Jan-Mar 2011 \\
\hline Team 3 & $\begin{array}{l}\text { Jan-early Mar } \\
2011\end{array}$ & $\begin{array}{l}\text { Late Mar-May } \\
2011\end{array}$ \\
\hline Team 4 & $\begin{array}{l}\text { Jan-early Mar } \\
2011\end{array}$ & $\begin{array}{l}\text { Late Mar-May } \\
2011\end{array}$ \\
\hline
\end{tabular}

to one medical team, meaning she delivered service to patients of one treating consultant across multiple wards, enabling her integration into the medical team. Two clinical pharmacists contributed to PACT, one delivered service to teams 1,2 and 3 , and the other to team 4, with each providing holiday relief for the other. They both held a Masters in Hospital Pharmacy, NFQ Level 9, and the General Level Framework. ${ }^{32}$ The PACT intervention aligns with Level 4 of the FIP model of CPP. ${ }^{29}$

\section{Outcome measures}

Primary outcomes measured comprised the prevalence per patient of

- any medication error identified by reconciliation or in the writing of a new prescription, following admission and discharge (here-on referred to as error);

- an error with the potential to cause severe patient harm. ${ }^{33}$

MedRec was defined based on the IHI's process, identifying inclusion of unintentional changes and intentional but undocumented changes to medication as failure to reconcile. ${ }^{6}$ This study investigated errors identified at admission and discharge and not those between these two points. Error was defined as a prescription writing error that was identified by reconciliation or in the writing of new medication orders at admission or discharge. $^{2} 34$ The clinical pharmacist's medication history was regarded as the gold standard preadmission medication list (GSPAML) against which reconciliation was assessed. The medication history was built using a previously developed method. ${ }^{11}$ Data from the following sources were used prospectively by the investigator to identify errors: GSPAML; drug chart; discharge medication list (prescription and summary); all entries in the healthcare record regarding medication use. Identified discrepancies were clarified as intentional or not, by reference to the medical team and/or clinical pharmacist. Every identified discharge error was presented, in the form of a case study outlining clinical, diagnostic and medication details, to six independent assessors, blinded to study allocation, who retrospectively scored the potential for harm using a validated, reliable visual analogue scale (VAS) $(0=$ no harm, $10=$ death $^{33}$ previously used for this purpose. ${ }^{2} 35$ Assessors included hospital and community pharmacists, hospital doctors and general practitioners. The mean score for each error was calculated from the individual VAS scores of the six assessors and categorised as minor $(<3)$, moderate $(3-7)$ or severe $(>7)$. Where a patient experienced multiple errors, the highest scoring error was used to describe the potential for harm to that patient.

Secondary outcome measures were

- quality of prescribing in patients aged $\geq 65$ years, using the Medication Appropriateness Index (MAI); ${ }^{36}$

- frequency of acceptance of clinical pharmacists' documented suggestions.

MAI, a tool validated to assess prescribing quality in patients aged $\geq 65$ years, has good inter-rater reliability. ${ }^{37}$ It comprises ten weighted categories, allowing a total sum of 18 marks for each drug, with increasing scores representing inferior quality: (indication (3); population effectiveness (3); dosage correct (2); directions correct (2); directions practical (1); drug-drug interactions (2); drug-disease interactions (2); cost (1); unnecessary duplication (1) and duration (1)). The weighted score is applied if 'inappropriate' is selected. Where a medication was unintentionally omitted or intentionally stopped or withheld but not documented on the discharge list, it was categorised as 'directions correct-inappropriate'. MAI was applied retrospectively by one of two investigators, with quality assurance on the data entry for a randomly selected $10 \%$ of patient cases by a third investigator. The investigators were not blinded to study allocation and had access to all sources of medication and clinical details in the healthcare record. MAI was applied on three medication lists: preadmission, during admission and discharge. The summated score for each patient at each stage and the differences from preadmission to admission and from preadmission to discharge were calculated. $^{27} 38$ Underuse of medication, that is, whether each of the patient's present medical conditions or risk factors was treated, was not assessed.

\section{Data management}

The sample size calculation was based on the primary outcome. Prevalence per patient of medication error on 
discharge was previously identified as $50-66 \% .^{2} 39$ To demonstrate a reduction from $60 \%$ to $40 \%,{ }^{21} 40-42$ $90 \%$ power, $5 \%$ significance level (two-sided) required 130 per group, total 260 patients. Review of hospital discharge statistics indicated that this sample size was achievable by allowing 2 months PACT service delivery for each of the four teams. The unit of assignment was the team, and the unit of analysis was the patient. Data collection was undertaken by clinical pharmacist investigators who were not involved in delivering the intervention. Data collection was ambispective happening during hospitalisation (error) and after discharge (MAI, VAS). Data were inputted into SPSS, V.18, and STATA, V.11, for support in analysis. Double data entry was undertaken by a second investigator on a randomly selected $10 \%$ of patient cases to assure quality. Errors at discharge were validated by two independent assessors, both clinical pharmacists, blinded to study allocation, and the level of agreement with the main investigator was measured using Cohen's $\kappa$ coefficient. Data distribution was analysed using the Kolmogorv-Smirnov test. Differences between groups were identified using the $\chi^{2}$ test for categorical data, Mann-Whitney U (reporting median and interquartile range) for non-parametric continuous data and the Student $t$ test (reporting mean and SD) for parametric continuous data. Prevalence of error was analysed using multilevel logistic regression, adjusting for length of stay; Charlson comorbidity index ${ }^{43}$; age and number of medications and accounting for any clustering effect at the level of the team. The number needed to treat (NNT) to prevent one patient

Table 3 Patients' demographic and clinical characteristics, intervention and standard care

\begin{tabular}{|c|c|c|c|}
\hline Characteristic & $\begin{array}{l}\text { Standard } \\
(n=121)\end{array}$ & $\begin{array}{l}\text { Intervention } \\
(n=112)\end{array}$ & p Value \\
\hline Gender, $\mathrm{n}(\%)$, male & $49(40.5)$ & $52(46.4)$ & 0.217 \\
\hline $\begin{array}{l}\text { General medical service* } \\
\text { status, }(\%) \text { in receipt }\end{array}$ & $72(50.0)$ & $61(55.0)$ & 0.260 \\
\hline $\begin{array}{l}\text { Employment status, (\%) } \\
\text { working }\end{array}$ & $56(46.3)$ & $49(44.1)$ & 0.423 \\
\hline $\begin{array}{l}\text { Smoking status, (\%) } \\
\text { current user }\end{array}$ & $36(29.8)$ & $37(33.0)$ & 0.690 \\
\hline $\begin{array}{l}\text { Alcohol use, (\%) current } \\
\text { user }\end{array}$ & $53(43.8)$ & $46(41.1)$ & 0.773 \\
\hline Age, years, median (IQR) & $64(52-75)$ & $62(54-77)$ & 0.922 \\
\hline Age $\geq 65$ years, $n(\%)$ & $60(49.6)$ & $48(42.9)$ & 0.369 \\
\hline $\begin{array}{l}\text { Length of stay, days, } \\
\text { median (IQR) }\end{array}$ & $6(4-12)$ & $7(4-12)$ & 0.593 \\
\hline $\begin{array}{l}\text { Charlson comorbidity } \\
\text { index, median (IQR) }\end{array}$ & $2(1-3)$ & $1(1-3)$ & 0.915 \\
\hline $\begin{array}{l}\text { Number of medicinest, } \\
\text { median (IQR) }\end{array}$ & $10(7-12)$ & $9(7-13)$ & 0.727 \\
\hline
\end{tabular}

*General Medical Service refers to government support for healthcare, including general practitioner visits and prescribed medication, eligibility is largely based on income.

tRelates to the total number of medicines prescribed before admission and those added during admission that remained active at discharge, exclusive of medications commenced and stopped within the hospital episode. experiencing any error and a potentially severe discharge error was calculated using the NewcombeWilson hybrid score $\mathrm{CI}^{44}$ Extreme scenario analysis provided sensitivity analysis to account for cases of missing data for the primary outcome, providing 95\% CIs around each extreme case. ${ }^{45}$

Approval was obtained from the St James's Hospital/ Tallaght Hospital Joint Research Ethics Committee (SJH/AMNCH REC ref 2010/03/11). It was considered an investigation of service delivery, all investigators were employed clinicians, contractually bound to maintain patient confidentiality. Patient consent was not required. Guidance for undertaking observational studies ${ }^{46}$ and non-randomised designs ${ }^{47}$ was followed. As this involved prospective observation, the investigators were ethically obliged to report any identified reconciliation errors at discharge to the treating team or clinical pharmacist to facilitate remedial action.

\section{FINDINGS}

A total of 233 patients were recruited (table 2). There were no differences in baseline clinical or demographic characteristics between the 121 standard care and 112 intervention patients (table 3). Some 2324 medications were surveyed, the majority were cardiovascular (33\%), central nervous system (16\%), respiratory (11\%), gastrointestinal (11\%) and endocrine (9\%). For 24 patients $(10.3 \%)$, the primary outcome was not assessable because the discharge documentation was not completed. These patients were identified as being younger and were more likely to receive standard care (see online supplementary file 1).

\section{Primary outcome measures}

Medication errors were identified in $25.4 \%$ of patients at admission and $34.8 \%$ at discharge. The two blinded assessors agreed with the identification of an error for 201 of the 202 implicated drugs, representing substantial agreement for each assessor with the main investigator $(\kappa=0.8) .{ }^{48}$

Patients receiving standard care were statistically significantly more likely to experience an error at admission $\left(40.5 \%\right.$ vs $9.0 \%, \gamma^{2}=30.3$, df $\left.1, \mathrm{p} 0.000\right)$ and discharge $\left(65.3 \%\right.$ vs $13.9 \%, \gamma^{2}=58.2$, df 1 , p 0.000$)$ than those receiving the intervention. Patients receiving standard care had a greater likelihood of experiencing a potentially severe discharge error $\left(5.9 \%\right.$ vs $\left.0, \gamma^{2}=6.6, \mathrm{df} 1, \mathrm{p} 0.012\right)$ (table 4). The variable that dominated the logistic regression models for experiencing an error at admission or discharge was the study group, demonstrating a protective effect by the PACT intervention. The only other variable statistically significantly associated with experiencing an error in these models was the number of medicines used per patient. For every extra medicine used, there was a $17 \%$ increased likelihood of error (95\% CI 6 to 29\%). The NNT to prevent any discharge error was 3 (95\% CI 2 to 3 ) and to prevent a potentially severe discharge error 
Table 4 Primary outcome measures

\begin{tabular}{|c|c|c|c|c|c|}
\hline Outcome & $\begin{array}{l}\text { Prevalence } \\
\text { Standard, } \\
\text { n (\%) }\end{array}$ & $\begin{array}{l}\text { Intervention, } \\
\mathrm{n}(\%)\end{array}$ & $\begin{array}{l}\text { Goodness of fit } \\
\text { (Hosmer \& Lemeshow } \\
\text { test, Nagelkerke's } R^{2} \text { ) }\end{array}$ & $\begin{array}{l}\text { Unadjusted } \\
\text { OR, } 95 \% \mathrm{Cl}\end{array}$ & $\begin{array}{l}\text { Adjusted OR } \\
\text { accounting for } \\
\text { clustering, } 95 \% \mathrm{Cl}\end{array}$ \\
\hline Admission error, per patient & $49 / 121(40.5)$ & $10 / 112(9.0)$ & $0.737,0.239$ & $0.15,0.07$ to 0.30 & ${ }^{*} 0.14,0.07$ to 0.31 \\
\hline Discharge error, per patient & $66 / 101(65.3)$ & 15/108 (13.9) & $0.723,0.418$ & $0.09,0.04$ to 0.17 & t0.07, 0.03 to 0.15 \\
\hline $\begin{array}{l}\text { Extreme sensitivity analysis } \\
\text { Missing data treated as error present }\end{array}$ & $86 / 121(71.1)$ & $19 / 112(17.0)$ & $0.406,0.415$ & $0.08,0.04$ to 0.16 & t0.07, 0.04 to 0.14 \\
\hline $\begin{array}{l}\text { Missing data treated as error not } \\
\text { present }\end{array}$ & $66 / 121(54.5)$ & 15/112 (13.4) & $0.759,0.306$ & $0.13,0.07$ to 0.25 & t0.11, 0.06 to 0.23 \\
\hline \multicolumn{6}{|c|}{ Discharge: potential to cause harm $\neq, n(\%)$} \\
\hline No error, no harm (VAS score 0) & $35(34.7)$ & $93(86.1)$ & & & \\
\hline Minor harm (VAS score <3) & $6(5.9)$ & $2(1.9)$ & & & \\
\hline Moderate harm (VAS score 3-7) & $54(53.5)$ & $13(12.0)$ & & & \\
\hline Severe harm (VAS score >7) & $6(5.9)$ & $0(0)$ & & & \\
\hline $\begin{array}{l}\text { VAS score for potential harm } \neq \\
\text { (median, IQR) }\end{array}$ & $4(0$ to 5$)$ & $0(0$ to 0$)$ & Mann-Whitney U p 0.000 & & \\
\hline \multicolumn{6}{|c|}{$\begin{array}{l}\text { *Multilevel logistic regression, adjusted for Charlson comorbidity index, number of medicines (relates to the total number of medications prescribed before } \\
\text { admission and those added during admission that remained active at discharge, exclusive of medications commenced and stopped within the hospital } \\
\text { episode), age. } \\
\text { †Multilevel logistic regression, adjusted for Charlson comorbidity index, number of medicines (relates to the total number of medications prescribed before } \\
\text { admission and those added during admission that remained active at discharge, exclusive of medications commenced and stopped within the hospital } \\
\text { episode), age, length of stay. } \\
\text { †Calculated across all } 209 \text { patients for whom the primary outcome measure was available, with a value of } 0 \text { applied for no error. } \\
\text { VAS, visual analogue score. }\end{array}$} \\
\hline
\end{tabular}

was 20 (95\% CI 10 to 142$)$. (See online supplementary file 2 for examples of errors in each severity category.)

Extreme sensitivity analysis, accounting for missing primary outcome data, identified consistently that the PACT intervention protected against the occurrence of any error (table 4).

The drug categories most commonly implicated in error relative to their frequency of use, by British National Formulary (BNF) classification, were $(\%=$ percentage of errors of the total number of drugs surveyed in that BNF class, $\mathrm{n}=$ number of errors): anaesthesia $(100 \%, \mathrm{n}=1)$; ear, nose and oropharynx $(33 \%, \mathrm{n}=1)$; musculoskeletal and joint diseases $(22 \%, \mathrm{n}=11)$; obstetric, gynaecology and urinary tract $(21 \%, n=4)$. However, medications that accounted for the greatest proportion of errors, owing to the higher prevalence of use, were cardiovascular $(8.1 \%, \mathrm{n}=55)$; central nervous system $(11.3 \%, \mathrm{n}=36)$, respiratory system $(11.1 \%$, $\mathrm{n}=25)$ and endocrine system $(13.1 \%, \mathrm{n}=24)$.

\section{Secondary outcome measures}

Medication Appropriateness Index

Of the 233 patients recruited to the study, 108 were aged 65 years or older $(43 \%$ of the intervention group, $50 \%$ of standard care) and eligible to apply the MAI tool. MAI was applied to all 108 patients at the stages preadmission and admission, but to 102 patients' discharge lists (data missing for six standard care patients who did not have discharge medication lists prepared). There was no difference between the groups in the median summated MAI score applied to the GSPAML (table 5), indicating a similar quality of prescribing before admission to hospital. The quality of prescribing during admission and at discharge deteriorated in patients receiving standard care and improved for intervention patients (table 5).

\section{Clinical pharmacist suggestions}

The PACT clinical pharmacists documented suggestions to optimise medication use more frequently than the standard care clinical pharmacists (table 5). The most common types of intervention were notification of an omitted medication $(40.8 \%$ and $54.7 \%$ of the intervention and standard care suggestions, respectively); dose correction or clarification $(34.2 \%$ and 26.9\%); commission (the unintentional addition of a medication the patient was not actually using) (8.5\% and $7.5 \%$ ); frequency of administration correction or clarification $(6.9 \%$ and $5.5 \%)$; and other $(9.6 \%$ and $5.5 \%)$. These suggestions were more likely to be accepted for patients receiving the intervention and to be accepted earlier, during the admission rather than at discharge, in the hospital episode (table 5).

\section{DISCUSSION}

The main findings of this study are that the PACT intervention is effective at reducing the prevalence per patient of error at admission and discharge from adult medical inpatient care, preventing potentially severe error and facilitating clinical pharmacy input to improve medication use. PACT improved the quality of prescribing in medical patients aged 65 years and older.

The finding that PACT, integrating clinical pharmacy service with medical care, with a focus at admission and discharge, reduced the prevalence of error is consistent 
Table 5 Secondary outcome measures

\begin{tabular}{|c|c|c|c|}
\hline Outcome & Standard & Intervention & p Value \\
\hline \multicolumn{4}{|l|}{ MAI, median (IQR) } \\
\hline Summated MAI pre-admission & $3(1$ to 6.8$)$ & $4(1$ to 7.5$)$ & 0.538 \\
\hline Summated MAI admission & $4(2$ to 7$)$ & $2.5(1$ to 5$)$ & 0.013 \\
\hline Summated MAI discharge & 6 (3 to 9$)$ & $2(0$ to 4$)$ & 0.000 \\
\hline Difference preadmission to admission, summated MAI & $0(-2$ to 4$)$ & $-0.5(-3$ to 0$)$ & 0.006 \\
\hline Difference preadmission to discharge, summated MAI & $1(-1$ to 6$)$ & $-1(-3.8$ to 0$)$ & 0.000 \\
\hline Process measures & & & $\chi^{2}, p$ value, $d f$ \\
\hline Clinical pharmacist suggestion made per patient, n (\%) & $73 / 121(60.3 \%)$ & $86 / 112(76.8 \%)$ & $7.3,=0.005,1$ \\
\hline Clinical pharmacist suggestion made per medication, $\mathrm{n}(\%)$ & $200 / 1231(16.2 \%)$ & $261 / 1093(23.9 \%)$ & $21.2,=0.000,1$ \\
\hline \multicolumn{4}{|l|}{ Acceptance of clinical pharmacist suggestions $n(\%)$ of suggestions } \\
\hline Accepted during admission & $111(55.5 \%)$ & $240(92.0 \%)$ & $91.9,=0.000,2$ \\
\hline Accepted at discharge & $24(12.0 \%)$ & $16(6.1 \%)$ & \\
\hline Not accepted & $65(32.5 \%)$ & $5(1.9 \%)$ & \\
\hline
\end{tabular}

MAI, Medication Appropriateness Index (increase in score represents reduction in quality of prescribing).

with international findings. ${ }^{14} 21264042$ 49-52 The PACT effect size seems larger than that achieved in other pharmacist-led interventions that measured medication error or discrepancy. ${ }^{21} 40-4253$ The exception was Vasileff $e t \mathrm{al}^{16}$, a study undertaken in an Australian emergency department in patients aged $60+$ using $4+$ drugs, identifying $72 \%$ absolute reduction in prevalence of unintentional discrepancy per patient. The observed effect size may be related to differences in the study populations and their underlying risk for medication misadventure. The evidence from this study supports the involvement of the clinical pharmacist in medication management across the entire inpatient episode, inclusive of discharge. Consistent with other studies, we identified that an increasing number of medications is associated with likelihood of experiencing an error. ${ }^{2}{ }^{15}$ However, although previous studies targeted patients with increasing comorbidity burden or of advancing age, ${ }^{14} 163854$ we did not identify a correlation between either of these variables and the presence of an error. The evidence from this study supports targeting the PACT intervention to patients using a greater number of medications.

We identified that the quality of prescribing deteriorated in patients receiving standard care and improved with the PACT intervention. A recent Cochrane systematic review identified that inappropriate polypharmacy is a particular concern in older people and is associated with negative health outcomes: complex, multifaceted pharmaceutical care demonstrated a mean difference of -6.78 in MAI score from pooled data of four studies. ${ }^{55}$ Direct comparison to the effect size in our study is difficult because our data were not normally distributed; however, the PACT effect, in this regard, appears to be modest. Two of the four studies reported in the Cochrane review involved collaborative working between pharmacists and medical practitioners. $^{28} 56$ The Integrated Medicines Management (IMM) services in Northern Ireland and Sweden achieved similar improvements in MAI score as our study ${ }^{27} 38$ and these findings support the collaborative model of medicines management between physicians and pharmacists to improve prescribing quality for older hospitalised patients.

As with any complex intervention, it is difficult to attribute success to any single 'active ingredient' or component of the intervention. ${ }^{57}$ However, the collaborative nature of this intervention is worthy of discussion. Collaborative prescribing requires a collegiate relationship between a pharmacist and a medical practitioner with legal authority to prescribe. ${ }^{58}$ It has been identified as a form of dependent prescribing, that being where authority to prescribe is delegated from an independent prescribing professional to a healthcare professional without such authority. ${ }^{58}$ The PACT intervention allowed for the clinical pharmacist, in consultation with the medical team, to make major and minor changes to the patient's drug chart or the discharge medication list. These activities are consistent with the notion of collaborative prescribing. There is evidence that collaborative prescribing reduces the prevalence of medication error and unintentional discrepancy in the emergency department and perioperative settings. ${ }^{16} 59$ 60 This is consistent with our finding that PACT patients experienced more clinical pharmacist's recommendations that were accepted more frequently and earlier in the hospital episode than standard care, coupled with a reduction in error and an improvement in quality of prescribing. The lower frequency of, and delay in, standard care clinical pharmacist's recommendation acceptance demonstrates an inefficiency in standard care. Possible contributing factors include an absence of physician recognition of the pharmacist's contribution, as previously described in a London hospital, ${ }^{61}$ or inferior collaboration and teamwork in the ward-based model. However, this is countered by the estimation that PACT pharmacists were able to see approximately $70 \%$ the volume of patients as the standard service, meaning that PACT is $40 \%$ more 
intensive in terms of clinical pharmacy resource. In times of budgetary constraint, it will be important to investigate the health economics of PACT and this is the focus of the current research. The findings of the study demonstrate that integration of a more advanced level of CPP as described by FIP, with greater responsibility for the pharmacist, yields benefits for patient safety. ${ }^{29}$ It is important to say that this should be supported by appropriately qualified and credentialed pharmacists. ${ }^{58} 62$

There are a number of limitations to this study. An uncontrolled before-after study is regarded as inferior to a controlled or a randomised study design: changes that occur over time make it difficult to attribute any observed change to the intervention; there is evidence that the results of such studies may overestimate the effects of quality improvement-like interventions. ${ }^{63}$ It was not feasible to undertake a randomised controlled study at a single centre due to potential for contamination across the care of patients receiving standard or intervention care by either the pharmacists or the doctors. However, every effort was taken to minimise bias due to non-randomisation and no difference was identified in baseline demographic or clinical characteristics between the study groups. Extreme sensitivity analysis accounted for missing primary outcome data and the findings were consistent at each extreme, demonstrating the positive effect of PACT to prevent error. In this study, the GSPAML was held as the most accurate reflection of the patient's medication use and a rigorous process was followed to compose this list. ${ }^{1164}$ Despite this, it is known that it is difficult to identify a patient's actual medication use and it is possible that the GSPAML was not always accurate, presenting a potential bias. ${ }^{64}$ Target sample size was not achieved, largely because a large proportion of patients were transferred to another medical team following admission. Nonetheless, the study was adequately powered to identify the magnitude of change in the primary outcome measure with 90\% power at the $5 \%$ significance level. The proportions of the study population who were male $(46.6 \%$ nationally) and medical card holders (53.5\% nationally) are comparable to adult inpatients receiving acute hospital care nationally. ${ }^{65}$ However, the study population were older and had lengthier hospital stay than the national average. This is likely because we selected patients using at least three regular medications on admission, and it is known that length of stay $^{65}$ and number of drugs used per patient ${ }^{66}$ increase with advancing age. This supports external generalisability of the efficacy of the intervention to older patients using at least three regular medications on admission rather than to all adult inpatients. ${ }^{65} 67$ Only two clinical pharmacists were involved in delivering the PACT intervention. This limits the generalisability of the study. However, both held Masters in Hospital Pharmacy and were certified General Level
Framework, which may support generalisability to other clinical pharmacists with equivalent credentials. $^{32}$

As is the case with most prospective observation, the main investigator was required to intervene to remediate and mitigate harm consequent to identified reconciliation errors at discharge. This limited the opportunity to assess the impact of the intervention on healthcare use or the presence of ADEs after discharge. Few studies ${ }^{51} 6869$ have investigated the effect of MedRec interventions on ADEs, likely due to the complexity, high cost and resource intensiveness of identifying this outcome. ${ }^{51} \mathrm{ADE}$ and healthcare use are regarded as ideal outcome measures in studies of medication management because they represent actual patient outcomes. ${ }^{70}$ There is debate regarding the validity of ADEs or healthcare use as outcome measures of MedRec interventions: it is argued that the harm consequent to reconciliation error may not become apparent for months after discharge. ${ }^{13}$ Furthermore, the causality between MedRec interventions and ADE or healthcare use following discharge is difficult to establish, given the opportunities for medication change and other confounders that may occur in the interim. Therefore, we believe our choice of outcome measures is valid and pragmatic.

PACT improved the quality and safety of prescribing for medical patients receiving acute hospital care: it reduced the prevalence of all medication error and potentially severe error; it improved the quality of prescribing in patients aged 65 years or older. The recommendations are to implement collaborative models of medication management between medicine and pharmacy and to facilitate collaborative prescribing by pharmacists within this model.

Acknowledgements We acknowledge the support of The Meath Foundation who funded this research. We acknowledge clinicians' contributions to assess the potential for patient harm consequent to error, including Dr Hugh Nohilly, Dr Aisling ni Shuilleabhain, Dr Brendan O'Shea, Dr Patrick Redmond, Mr John Barry, Mrs Cicely Roche, Ms Caitriona Gowing, Dr Michelle O'Shaughnessey, Dr Abi Subra and Dr Safwat Hamad. We are grateful to Prof. Tom Fahey for his critical review of the manuscript; Prof. Kathleen Bennett for her critical review of the manuscript and biostatistical support; Prof. Mike Scott and Ms Anita Hogg for collaboration and sharing of experiences delivering IMM in Northern Ireland; and Prof. Joseph Hanlon for his guidance on the use of the MAI. We thank Mrs Maria Tallon, who supported data entry, and Ms Michelle Fitzsimons and Ms Jennifer Hayde, who contributed to delivering the PACT intervention. The medical, nursing, pharmacy and administrative staff and the participating patients made this study possible.

Contributors All authors had full access to all the data in the study and can take responsibility for the integrity of the data and the accuracy of the data analysis. TCG, ED, AA, JO'B, TD, $\mathrm{JB}, \mathrm{NB}, \mathrm{EM}$ and $\mathrm{CW}$ were responsible for study design.TCG and MT were responsible for acquisition of data. All authors were responsible for analysis and interpretation of data. TCG and ED were responsible for drafting of the manuscript. TCG, $\mathrm{ED}, \mathrm{AA}, \mathrm{JO}$ 'B, TD, JB, NB, EM and CW were responsible for critical revision of the manuscript for important intellectual content. TCG supervised the study. 
Funding This study was supported by a Research Grant from The Meath Foundation.

\section{Competing interests None.}

Ethics approval SJH/AMNCH Research Ethics Committee.

Provenance and peer review Not commissioned; externally peer reviewed.

Data sharing statement Data available on request from the corresponding author.

Open Access This is an Open Access article distributed in accordance with the Creative Commons Attribution Non Commercial (CC BY-NC 3.0) license, which permits others to distribute, remix, adapt, build upon this work noncommercially, and license their derivative works on different terms, provided the original work is properly cited and the use is non-commercial. See: http://creativecommons.org/licenses/by$\mathrm{nc} / 3.0 /$

\section{REFERENCES}

1 Forster AJ, Murff HJ, Peterson JF, et al. Adverse drug events occurring following hospital discharge. J Gen Intern Med 2005;20:317-23.

2 Grimes T, Duggan C, Delaney T, et al. Medication details documented on hospital discharge: cross sectional observational study of factors associated with medication non-reconciliation. Br J Clin Pharmacol 2011;71:449-57.

3 Mueller SK, Sponsler KC, Kripalani S, et al. Hospital-based medication reconciliation practices: a systematic review. Arch Intern Med 2012;172:1057-69.

4 Tam VC, Knowles SR, Cornish PL, et al. Frequency, type and clinical importance of medication history errors at admission to hospital: a systematic review. CMAJ 2005;173:510-5.

5 The Society of Hospital Pharmacists of Australia (SHPA). SHPA standards of practice for the provision of medication reconciliation. J Pharm Pract and Res 2007;37:231-3.

6 Institute for Healthcare Improvement. Accuracy at every step: the challenge of medication reconciliation. 2006 [updated 2006; cited]; http://www.ihi.org/IHI/Topics/PatientSafety/ MedicationSystems/ImprovementStories/AccuracyatEveryStep. htm (accessed 15 Mar 2013).

7 Madden D. Building a culture of patient safety. Report of the Commission on Patient Safety and Quality Assurance. Dublin: Department of Health and Children, 2008. http://www.dohc.ie/ publications/building_culture_patient_safety.html (accessed 29 May 2013).

8 National Institute for Health and Care Excellence (NICE)/ National Patient Safety Agency (NPSA). Technical patient safety solutions for medicines reconciliation on admission of adults to hospital: NICE/NPSA; PSG001 2007. http://guidance.nice.org. uk/PSG001 (accessed 29May 2013).

9 National Prescribing Centre. Medicines reconciliation: a guide to implementation. Good Practice Guides. 2008 [updated 2008; cited 2010 25/05/2010]. http://www.npc.nhs.uk/ improving_safety/medicines_reconciliation/resources/ reconciliation_guide.pdf (accessed 29 May 2013).

10 Joint Commission on Accreditation of Healthcare Organizations, USA. Using medication reconciliation to prevent errors. Sentinel Event Alert 2006;23:1-4.

11 Fitzsimons M, Grimes T, Galvin M. Sources of pre-admission medication information: observational study of accuracy and availability. Int J Pharm Pract 2011;19:408-16.

12 Greenwald JL, Halasyamani LK, Greene J, et al. Making inpatient medication reconciliation patient centered, clinically relevant, and implementable: a consensus statement on key principles and necessary first steps. Jt Comm J Qual Patient Saf 2010;36:504-13.

13 Kwan JL, Lisha L, Sampson M, et al. Medication reconciliation during transitions of care as a patient safety strategy. A systematic review. Ann Intern Med 2013;158:397-403.

14 Gillespie U, Alassaad A, Henrohn D, et al. A comprehensive pharmacist intervention to reduce morbidity in patients 80 years or older: a randomized controlled trial. Arch Intern Med 2009;169:894-900.

15 Hellstrom LM, Bondesson A, Hoglund P, et al. Errors in medication history at hospital admission: prevalence and predicting factors. BMC Clin Pharm 2012;12:9.

16 Vasileff HM, Whitten LE, Pink JA, et al. The effect on medication errors of pharmacists charting medication in an emergency department. Pharm World Sci 2009; 31:373-9.

17 Gallagher P, O’Mahony D. STOPP (Screening tool of older persons' potentially inappropriate prescriptions): application to acutely ill elderly patients and comparison with Beers' criteria. Age Ageing 2008;37:673-9.

18 Wahab MS, Nyfort-Hansen K, Kowalski SR. Inappropriate prescribing in hospitalised Australian elderly as determined by the STOPP criteria. Int J Clin Pharm 2012;34:855-62.

19 Bradley MC, Fahey T, Cahir C, et al. Potentially inappropriate prescribing and cost outcomes for older people: a cross sectional study using the Northern Ireland Enhanced Prescribing Database. Eur J Clin Pharmacol 2012; 68:1425-33.

20 Cahir C, Fahey T, Teeling M, et al. Potentially inappropriate prescribing and cost outcomes for older people: a national population study. Br J Clin Pharmacol 2010;69:543-52.

21 Bergkvist A, Midlov P, Hoglund P, et al. Improved quality in the hospital discharge summary reduces medication errors--LIMM: Landskrona Integrated Medicines Management. Eur J Clin Pharmacol 2009;65:1037-46.

22 Gillespie U, Alassaad A, Hammarlund-Udenaes M, et al. Effects of pharmacists' interventions on appropriateness of prescribing and evaluation of the instruments' (MAI, STOPP and STARTs') ability to predict hospitalization - analyses from a randomized controlled trial. PLOS ONE 2013;8:e62401.

23 Hellstrom LM, Bondesson A, Hoglund P, et al. Impact of the Lund Integrated Medicines Management (LIMM) model on medication appropriateness and drug-related hospital revisits. Eur J Clin Pharmacol. 2011;67:741-52.

24 O'Connor MN, Gallagher P, Byrne S, et al. Adverse drug reactions in older patients during hospitalisation: are they predictable? Age Ageing 2012;41:771-6.

25 Karapinar-Carkit F, Borgsteede SD, Zoer J, et al. The effect of the $\mathrm{COACH}$ program (Continuity Of Appropriate pharmacotherapy, patient Counselling and information transfer in Healthcare) on readmission rates in a multicultural population of internal medicine patients. BMC Health Serv Res 2010;10.

26 Scullin C, Scott MG, Hogg A, et al. An innovative approach to integrated medicines management. J Eval Clin Pract 2007;13:781-8.

27 Burnett KM, Scott MG, Fleming GF, et al. Effects of an integrated medicines management program on medication appropriateness in hospitalized patients. Am J Health-Syst Pharm 2009;66:854-9.

28 Spinewine A, Swine C, Dhillon S, et al. Effect of a collaborative approach on the quality of prescribing for geriatric inpatients: a randomized, controlled trial. J Am Geriatr Soc 2007;55:658-65. 
29 International Pharmaceutical Federation (FIP). Reference paper collaborative practice. The Hague, The Netherlands, 2009. https://www.fip.org/www/uploads/database_file.php? id=319\&table_id= (accessed 29 May 2013).

30 Grimes T, Duggan C, Delaney T. Hospital pharmacy services at admission and discharge in adult, acute, public hospitals in Ireland. Int J Pharm Pract 2010;18:346-52.

31 The Pharmaceutical Society of Ireland Baseline Study of Hospital Pharmacy in Ireland. Dublin, 2012. http://www.thepsi. ie/Libraries/Publications/PSI_Hospital_Baseline_Study_Report_ 2012.sflb.ashx (accessed 29 May 2013).

32 Antonioui S, Webb DG, McRobbie D, et al. A controlled study of the general level framework: Results of the South of England competency study. Pharm Educ 2005;5:201-7.

33 Dean BS, Barber ND. Validated, reliable method of scoring the severity of medication errors. Am J Health-Syst Pharm 1999;56:57-62.

34 Dean B, Barber N, Schachter M. What is a prescribing error? Qual Health Care 2000;9:232-7.

35 Galvin M, Jago-Byrne MC, Fitzsimons M, et al. Clinical Pharmacist's contribution to medication reconciliation on admission to hospital in Ireland. Int J Clin Pharm 2013;35:14-21.

36 Hanlon JT, Schmader KE, Samsa GP, et al. A method for assessing drug therapy appropriateness. J Clin Epi 1992;45:1045-51.

37 Spinewine A, Dumont C, Mallet L, et al. Medication appropriateness index: reliability and recommendations for future use. J Am Geriatr Soc 2006;54:720-2.

38 Bergkvist A, Midlov P, Hoglund P, et al. A multi-intervention approach on drug therapy can lead to a more appropriate drug use in the elderly. LIMM-Landskrona Integrated Medicines Management. J Eval Clin Pract 2009;15:660-7.

39 Grimes T, Delaney T, Duggan C, et al. Survey of medication documentation at hospital discharge: implications for patient safety and continuity of care. Ir J Med Sci 2008;177:93-7.

40 Kwan Y, Fernandes OA, Nagge JJ, et al. Pharmacist medication assessments in a surgical preadmission clinic. Arch Intern Med 2007;167:1034-40.

41 Nickerson A, MacKinnon NJ, Roberts N, et al. Drug-therapy problems, inconsistencies and omissions identified during a medication reconciliation and seamless care service. Healthc $Q$ 2005;8:65-72.

42 Walker PC, Bernstein SJ, Jones JN, et al. Impact of a pharmacist-facilitated hospital discharge program: a quasi-experimental study. Arch Intern Med 2009;169:2003-10.

43 Charlson ME, Pompei P, Ales KL, et al. A new method of classifying prognostic comorbidity in longitudinal studies: development and validation. J Chronic Dis 1987;40:373-83.

44 Newcombe RG. Interval estimation for the difference between independent proportions: comparison of eleven methods. Stat Med 1998;17:873-90.

45 Cho Paik M, Sacco R, Lin I-F. Bivariate binary data analysis with nonignorably missing outcomes. Biometrics 2000;56:1145-56.

46 Vandenbroucke JP, Von Elm E, Altman DG, et al. Strengthening the reporting of observational studies in epidemiology (STROBE): explanation and elaboration. PLoS Med 2007;4:1628-54.

47 Des Jarlais DC, Lyles C, Crepaz N, et al. Improving the reporting quality of nonrandomized evaluations of behavioral and public health interventions: the TREND statement. Am J Public Health 2004;94:361-6.
48 Landis JR, Koch GG. The measurement of observer agreement for categorical data. Biometrics 1977;33:159-74.

49 Bolas H, Brookes K, Scott M, et al. Evaluation of a hospital-based community liaison pharmacy service in Northern Ireland. Pharm World Sci 2004;26:114-20.

50 Boockvar KS, Carlson LaCorte H, Giambanco V, et al. Medication reconciliation for reducing drug-discrepancy adverse events. Am J Geriatr Pharmacother 2006;4:236-43.

51 Boockvar KS, Santos SL, Kushniruk A, et al. Medication reconciliation: barriers and facilitators from the perspectives of resident physicians and pharmacists. J Hosp Med 2011;6:329-37.

52 Varkey P, Cunningham J, O'Meara J, et al. Multidisciplinary approach to inpatient medication reconciliation in an academic setting. Am J Health-Syst Pharm 2007;64:850-4.

53 Eggink RN, Lenderink AW, Widdershoven JW, et al. The effect of a clinical pharmacist discharge service on medication discrepancies in patients with heart failure. Pharm World Sci 2010;32:759-66.

54 Midlov P, Holmdahl L, Eriksson T, et al. Medication report reduces number of medication errors when elderly patients are discharged from hospital. Pharm World Sci 2008; 30:92-8.

55 Patterson S, Hughes C, Kerse N, et al. Interventions to improve the appropriate use of polypharmacy for older people. Cochrane Database Sys Rev 2012;: doi:10.1002/14651858.CD008165.pub2.

56 Crotty M, Rowett D, Spurling L, et al. Does the addition of a pharmacist transition coordinator improve evidence-based medication management and health outcomes in older adults moving from the hospital to a long-term care facility? Results of a randomized, controlled trial. Am J Geriatr Pharmacother 2004;2:257-64.

57 Craig P, Dieppe P, Macintyre S, et al. Developing and evaluating complex interventions: the new Medical Research Council guidance. BMJ 2008;337:a1655.

58 Emmerton L, Marriott J, Bessell T, et al. Pharmacists and prescribing rights: review of international developments. J Pharm Pharm Sci 2005;8:217-25.

59 Hale AR, Coombes IC, Stokes J, et al. Perioperative medication management: expanding the role of the preadmission clinic pharmacist in a single centre, randomised controlled trial of collaborative prescribing. BMJ Open 2013;3:e003027.

60 Marotti SB, Kerridge RK, Grimer MD. A randomised controlled trial of pharmacist medication histories and supplementary prescribing on medication errors in postoperative medications. Anaesth Int Care 2011; 39:1064-70.

61 Pullinger W, Franklin BD. Pharmacists' documentation in patients' hospital health records: issues and educational implications. Int J Pharm Pract 2010;18:108-15.

62 Coombes I, Avent M, Cardiff L, et al. Improvement in pharmacist's performance facilitated by an adapted competency-based General Level Framework. J Pharm Pract Res 2010;40:111-18.

63 Eccles M, Grimshaw J, Campbell M, et al. Research designs for studies evaluating the effectiveness of change and improvement strategies. Qual Saf Health Care 2003;12:47-52.

64 Pippins JR, Gandhi TK, Hamann C, et al. Classifying and predicting errors of inpatient medication reconciliation. J Gen Intern Med 2008;23:1414-22.

65 Economic and Social Research Institute (ESRI). Activity in acute public hospitals in Ireland. Health research and information division. Annual report 2010. Dublin: ESRI and Department of 
Health and Children; 2011. http://www.esri.ie/health_ information/latest_hipe_nprs_reports/ (accessed 29 May 2013).

66 Richardson K, Moore P, Peklar J, et al. Polypharmacy in Adults over 50 in Ireland: opportunities for cost saving and improved healthcare. Report from The Irish Longitudinal Study on Aging (TILDA), 2012. ISBN 978-1-907894-04-6. http://www.tcd.ie/ tilda/assets/pdf/polpharmacyreport.pdf (accessed 22 Nov 2013).

67 Health Service Executive (HSE). Primary care reimbursement service, statistical analysis of claims and payments 2011. Dublin: HSE 2012. http://www.hse.ie/eng/staff/PCRS/PCRS_ Publications/ (accessed 29 May 2013).
68 Kripalani S, Roumie CL, Dalal AK, et al. Effect of a pharmacist intervention on clinically important medication errors after hospital discharge: a randomized trial. Ann Intern Med 2012;157:1-10.

69 Schnipper JL, Kirwin JL, Cotugno MC, et al. Role of pharmacist counseling in preventing adverse drug events after hospitalization. Arch Intern Med 2006; 166:565-71.

70 Hanlon JT, Schmader KE, Semla TP. Update of studies on drug-related problems in older adults. J Am Geriatr Soc 2013;61:1365-8. 